\title{
The Elements Influence the Participation Rate of Chinese Students in Math Discussion in American Colleges
}

\author{
Ying $\operatorname{Liu}^{1, \mathrm{a}}$
}

\author{
${ }^{1}$ University of Oregon \\ ayliu23@uoregon.edu
}

\begin{abstract}
After seeing the different situations in online math discussion, the author is curious about the elements influence the participation rate of Chinese students in math discussion in American colleges. After doing the research, the author found most of research are talking about the offline discussions and use the quantitative method to get the models and analyzes. Little of them talking about a specific subject and use interview to get the point of students. The author interviewed 4 undergraduate Chinese students in an American college who took the online math discussion class and found the elements includes environment, language, difficulty to use technology, interest, difficulty of class and class arrangement. Interest and difficulty of class sometimes influenced each other and language and difficulty to use technology usually appear together.
\end{abstract}

Keywords: participation rate, Chinese students, American college, covid-19.

\section{INTRODUCTION}

From the beginning of 2020, as covid 19 spread seriously all over the world, many states in United States told their residents to stay at home [1]. At the same time, universities began to take an online approach for avoiding the situation that students gather and protect their health. Professors used some social media and technologies to help students have classes. For keeping the way of teaching and arouse the enthusiasm, some professors would still put the students into discussions and give them enough time to exchange their opinions online.

In college, the math online discussion is mainly for discussing the problems or brainstorming. After professors divide students into small groups in some math discussion classes, the author discovered that students either remain silent when professors do not enter the discussion groups or simply talk about something unrelated to the topics or questions and only speak up when professors enter the group. However, there is also the situation that the students are very excited and activated in discussing. The author wants to know the elements and factors influence the participation rate of Chinese students in online math discussion in an American college. To know the opinions of students, the author interviewed four Chinese students who took online discussion classes in American college after getting their permission and decide to use the case study to analyze these situations. The research could show the elements which will influence the participation of students and help both professors and students to consider how to manage or develop online math group discussions. To consider the elements influence participation in online math discussion classes, people should first know the definition of class participation. In 2006, Dr. Ken gave the descriptions of effective class description in 3 evaluate dimensions that all students are given the opportunities to participate by asking questions, offering examples when called for, and supply evidence of personal awareness of concepts germane to class discussion, take part in the class seriously without unfocused events and challenge the things they get from others but not forgetting the benefits[2].

\section{THE ANALYSIS OF THE FOUR MAIN CASES}

\subsection{The four cases}

The first case is the student said she got the math major not for interest but because she was better at math 
than other subjects. She took those discussions because they are required for graduation. She thought her participation rate was not high and she believed that it was influenced by several elements. She stated that if no one was talking, she would remain silent, and that the difficulty of the classes would also influence her because she would wish to speak more if she understands it. When she met the problems, she preferred waiting for professors to enter the discussion groups and asking the professors to explain the problems which she met, unless the team members are trying to discuss the point which she has. Besides that, she felt it is hard to use the computer to show some math symbols, when she wants to explain something but forget how to pronounce them. On the other hand, if the professor told her that it is an assignment and need to be graded, she would discuss it more and be more serious about the discussion. Furthermore, she believes that the teacher should devote some time at the end of the lesson to providing a summary or conclusion, otherwise the discussion will be futile. For the language and environment, she thought they were not very important but still have some influences.

The second student likes math and is good at math, so he chose math major and attended the math discussions. He did not like to have an online discussion because he often cannot hear others clearly through computer and it is hard for him to share things online. His participation rate is also dependent on other students. If he had some problems, he would first ask others and try to get solutions. However, he preferred to ask teachers. He preferred to discuss some specific questions than brainstorming because it brought him the feeling of achievement. The difficulty of the class is important because if the class is too hard, he did not know how to ask it and what to ask. When the topic was one which he was good at, he will try to lead the a discussion if others keep silent. When there was a worksheet related to discussion as homework, his participation would be higher if it is not graded, or he would use all the time to do it by himself. He believed when the professor gave the worksheet in advance and gave the whole class for discussion, it would be helpful to his participation. However, the most important thing for him is interest. As he said, he would have higher participation in the class if he liked that teacher and that field.

The third student was interested in math and chose the discussion class. He said he would be influenced by the environment like computers or smartphones. It was hard for him to focus on the discussion class. He would talk about something if someone else lead the conversation. When the professor gave a task, which was dependent on the discussion, he would increase his participation. Also, he said he preferred small and short discussions that teachers could give the conclusion of discussion and the longer one was hard to get efficiency. For him, the interest and difficulty of class could be one thing. When the class was not difficult and he learnt it well, he felt interested in it and he would like to participate more.

Finally, this student changed his major to math for he felt it fits him and he was interested in math. He cared about the time teacher gave them to discuss because sometimes he preferred to study alone and sometimes discuss with others. He thought his participation was good, but if he did not have a question, he would not talk much. The online discussion made him feel less pressure, but he thought it was hard to pay attention. He pointed that if he turned on the camera, he would have higher participation. Besides that, because he took an online class in China, the different time zone also influenced him. The interest and task increased his participation and brainstorming for him is better than solving solutions because there are more things to discuss.

\subsection{The influence factors of students' participation rate}

From these 4 cases, the author first finds that, most Chinese students have misunderstood participation. When the author interviewed them and asked about their situations, all the interviewees considered their discussion rate but not the participation rate. The wrong understanding influenced them sometimes to say a lot like a participation monopolize, which was not a good situation for participation [2].

Besides that, the author found the environment can influence students to some degree. The environment can be both physical and mental. Although some people said students can use both synchronous and asynchronous ways to study [5], as they put their phones on, it is hard for them to turn off their phones. In case 3 and 4, the author sees that online discussion is hard to monitor, students will have less pressure than before. Whether pay attention to the class depends on their selfconsciousness. Computer and mobile games are easier to influence students because students didn't need to worry about the oversaw from teachers. Also, for some students go back home and have online class, staying night caused by different time zone made them feel tired and hard to pay attention to class. As people know, math is all about logic, if students lost several steps for unconsciousness, it is hard to know the next steps. Therefore, the participation rate also decreases as the decrease of focus. In the discussion groups, the behavior of other group members will influence them. All of them expressed that when there is a leader in the group and activate the group members, they would try to take part in it, but if all people keep silent, they will keep silent. Only one person said he will first ask others the questions but if there are no people to answer, he will also keep silent the next. When the author asked the reason, they all said that they don't want to be the obvious one and don't want to embarrassed others and themselves. As in 
the mind of Chinese students, "face", "dignity" and interdependency are very important [3].

Another small element is language. It can also relate to the difficulty of technology use. The interviewees are most juniors or seniors and there are not many difficult words in math, they meet fewer situations caused by language. However, there exist some situations that students forget the name of some math symbols or Greek letters. Unlike in offline discussions, students can draw by hand directly, in online discussion, it is hard to draw or type on the computer. Even though students can search on the Internet immediately, it wasted time and interrupt the coherence and train of thought. If people want to share something which written by hand, it could be more difficult and take a longer time. In addition, all interviewees thought well spoken language can be connected to people's self-expression and selfconfidence. As people have a strong self-expression, they would more likely to take part in the discussion and play the role of leader [6].

The third element is interesting. There are 3 interviewees who have said they liked math. All these 3 people presented that if they are interested in the topic, or teacher, or content of class, they will increase their participation. In the interviews, two of them said that interest can be the most important element to them. If the class is interesting, even though it can be very difficult, they will participate actively for at that time, participation is not the grade but for interest.

Even though the huge interest can give them motivation to increase the participation rate, for those classes which are not very interesting, they are more influenced by the difficulty of the class. All these 4 interviewees had said that if the class is too difficult, they will not discuss anything. Two of them said that they do not know how to ask others and what to ask because they did not know anything. At that time, their participation will be extremely low because they cannot understand what others are talking about, but the dignity makes them feel embarrassed to ask especially when other students understand. In this case, they preferred to escaping from the discussion class and study by themselves which is against the purpose of discussion. One of them said the difficult class will whiling away the fun. In fact, he is less interested in math for several difficult and boring classes. At the same time, these 4 students all preferred asking professors after the class to asking in the group discussions. As $\mathrm{Lu}$ and Han cited in their research, Chinese graduates are accustomed to and tend to expect instructor-centered communication[3]. Chinese undergraduates are the same. Not for the dignity or face, but 2 students also felt guilty to disturb others' discussion and they thought it wasted others' time. They liked to go to the office hour and asked professors alone. Some of them thought the answers of other students could be not accurate and hard to understand, and the answer from professors are more direct. In this situation, they gave up the discussion and did other things.

The arrangement of class is also important. Although different students have different ideas, all of them hoped teachers can give the summary or conclusion in the ending. For those groups discussing some specific questions, students hope professors can give the answer or they didn't know the result of their discussion. No result brought bore to those students who get the feeling of achievement and confusion to those who were puzzled in the discussion. The participation rate will surely decrease. Another requirement from the students is to get the worksheet or questions in advance. It is hard for them to get the ideas and examples out directly. All students said their participation will increase if there are some tasks connected with the discussion like summary after discussion or small worksheet. For the discussion of brainstorming, students said the graded one will increase their participation because they want to get the ideas as much as possible, so that they can get good grades. For the discussing worksheet, some students liked to do it by themselves first and some like to discuss it together. The previous one gave up the discussion and keep silent and the latter is hard to control the time. They are both less efficient, but if the teacher can give them the questions in advance, all things are done.

\section{CONCLUSION}

In conclusion, the elements that influence the participation rate of Chinese students in math discussion in American colleges includes the environment, language, hard technology, interest, the difficulty of class and arrangement of class. If compared to other research, people can find that most big elements are similar. For example, "Influencing factors and improving countermeasures of college students' participation in online learning" also mentioned the difficulty of class and class arrangement [4]. Although the general reason is the same, the differences between online math discussion and other general online ones cause the differences in details. However, this research still has some disadvantages. All the interviewees are math majors and lack the voice of those who are not math major. They are all higher grades and lack the voices from freshmen or sophomores. The math discussion classes are mostly the requirement for graduation, so it lacks the situation that it is not required. The 4 interviewees are from the same school, in the later research, the author can try to find more undergraduates from other schools.

\section{REFERENCES}

[1] Mervosh, S., Lu, D \& Swales V. (2020, Apr 20) See Which States and Cities Have told Residents to Stay at Home. www.nytimes.com 
[2] Petress, K (2006) An operational definition of class participation. College Students Journal Dec 2006, Vol. 40 Issue 4, p821-823. 3p.

[3] Lu, C. \& Han, W. (2010). Why don't they participate? a self-study of Chinese graduate students' classroom: involvement in north America. Brock Education Journal, 20(1).

[4] Zhang, S (2021) The Influencing Factors and Improving Countermeasures of College Students' Participation in Online Learning. Economist. Issue 6, 2021. www.cnki.net

[5] Petty, T \& Farinde, A. A (2013 June). Investigating student engagement in an online mathematics course through windows into teaching and learning. MERLOT Journal of Online Learning and Teaching. Vol.9, No.2, June 2013

[6] Ying, N (2021). Improving students' enthusiasm of classroom participation: The breakthrough of Silent University classroom. JIAOYUGUANCHA. Vol.10, Issue.1, January 2020 